\title{
ESQUIZOAPRENDIZAGEM COMO POLÍTICA COGNITVA
}

\author{
ESQUIZOAPRENDIZAJE COMO POLÍTICA COGNITVA
}

Rubens Antonio Gurgel Vieira ${ }^{1}$

\begin{abstract}
Resumo: Este artigo buscou na filosofia da diferença de Deleuze e Guattari algumas pistas sobre o processo de aprendizagem. $O$ conceito de aprendizagem que circula desde a instauração de uma discursividade da sociedade aprendente no século $\mathrm{XX}$ possui rastros por toda a modernidade. Como resultado, temos uma ideia preconcebida de sujeito a ser formado a partir de uma série de procedimentos de ensino, dispositivos de criação dos alunos, todos muito bem enquadrados em rígidos modos de existência. Não obstante, conforme aprendemos com Foucault, não há poder sem resistência. A busca por uma resistência ocorre diante da impossibilidade de compreendermos a aprendizagem como um processo estruturado e transcendente, o que coloca em xeque as concepções clássicas herdeiras do pensamento moderno. Ao abraçar a imanência do processo de ensino, realizou-se uma incursão filosófica que produziu alguns indícios para afirmar a aprendizagem como transformação subjetiva profundamente relacionada com a produção desejante.
\end{abstract}

Palavras-chave: Aprendizagem; desejo; diferença.

Resumen: Este artículo buscó en la filosofía de la diferencia de Deleuze y Guattari algunas pistas sobre el proceso de aprendizaje. El concepto de aprendizaje que circula desde el establecimiento de un discurso de la sociedad del aprendizaje en el siglo XX tiene huellas en toda la modernidad. Como resultado, tenemos una idea preconcebida de un tema que se formará a partir de una serie de procedimientos de enseñanza, dispositivos para la creación de estudiantes, todo muy bien enmarcado en modos rígidos de existencia. Sin embargo, como aprendimos de Foucault, no hay poder sin resistencia. La búsqueda de resistencia se produce ante la imposibilidad de entender el aprendizaje como un proceso estructurado y trascendente, que pone en jaque los conceptos clásicos heredados del pensamiento moderno. Abrazando la inmanencia del proceso de enseñanza, se llevó a cabo una incursión filosófica que produjo alguna evidencia para afirmar el aprendizaje como una transformación subjetiva profundamente relacionada con la producción deseada.

Palabras clave: Aprendizaje; deseo; diferencia.

\section{O tema da aprendizagem na contemporaneidade}

$\mathrm{Na}$ herança cartesiana quem aprende é justamente um sujeito. Se para pensar há necessariamente um sujeito pensante, para aprender há um sujeito aprendente. Todavia, quando o limite é o cerne, a aprendizagem não pode ser entendida como resultado da ação de um sujeito estável e ciente do processo de autoconstrução. Precisamos de novas concepções de aprendizagem, concepções que entendam a subjetividade como produto de relações contínuas, uma constituição de uma experiência de si em conjunto com a criação de mundos - uma política cognitiva, portanto (KASTRUP; TEDESCO; PASSOS, 2015).

Na concepção psicológica hegemônica e mesmo no senso comum fruto do cartesianismo, quando falamos de aprendizagem imediatamente remetemos a um sujeito aprendente. Não à toa, as criações teóricas acerca da aprendizagem apresentadas pela psicologia do

\footnotetext{
${ }^{1}$ Doutor em Educação pela FE-Unicamp, Mestre em Educação pela FE-USP, docente FEFISO. Sorocaba. E-mail: rubens@fefiso.edu.br.
} 
desenvolvimento ancoradas na visão representacional do conhecimento estabelecem guias teóricos e métodos de ensino que buscam melhor adequar o sujeito ao mundo - um sujeito que compreende um mundo que é o mesmo para todos, regulado por leis universais, científicas. Entendemos que essa aprendizagem é, portanto, um processo de moralização que fere uma ética dos devires. Uma forma de entender a aprendizagem que não contempla os anseios de uma educação aberta e atiçadora de fluxos libertários, avessos à máquina social axiomatizante.

Existem infinitas formas de se conceber a aprendizagem - seja a partir da filosofia, da psicologia ou tantos outros campos filosóficos, científicos ou mesmo artísticos. O campo da aprendizagem, atravessado por infinitos planos de imanência, é marcado pela disputa de território, embate por poder de validação, envolto em relações socioculturais complexas que buscam impor suas concepções. Nesse sentido, interessa menos definir o que é aprendizagem, e mais apontar como uma determinada concepção possibilita operações didáticas potentes para um cotidiano escolar com aberturas para linhas de fuga.

Entretanto, mesmo que contando com infinitas produções conceituais, tal campo pode ser dividido em ao menos duas formas distintas de aprender: a recognição - ato de conceder resposta a um problema já formulado; e a invenção/criação - ato de criar os próprios problemas (GALLO, 2013). Por dentro de uma visão geofilosófica, Gallo entende que a educação ocidental possui uma matriz platônica, que coloca o aprender como uma recognição. Logo, o sentido da educação é acelerar o processo de reconhecimento das ideias perfeitas. A perspectiva recognitiva da educação acarreta em metodologias homogeneizantes e aos anseios do controle científico.

De forma complementar, Kastrup (1999) aponta a inexistência no campo da psicologia do tema invenção e afirma a necessidade de uma exploração dessa possibilidade. Ao reconhecer o forte caráter filosófico da questão, impossível de ser perseguida somente pelo viés psicológico moderno, a autora se coloca a pensar em novas formas de olhar para a cognição sem, no entanto, julgar outras perspectivas. A discursividade instaurada pela filosofia francesa contemporânea inspirou Kastrup, principalmente a partir de Deleuze e Bergson, a repensar o que é aprender, fugindo do campo da psicologia que entende aprender como conexão do sujeito a uma realidade única e concreta.

Para Gallina (2008), boa parte dos contextos de ensino não problematizam a aprendizagem, como se ela fosse uma consequência direta de como se pensa, organiza, efetiva e avalia dos métodos de ensino. Mas, para a autora, isso é um problema, pois não é o ensino que estabelece as condições do aprender, mas justamente o inverso, afinal somente um método aberto para invenções possibilita uma aprendizagem para além da atividade recognitiva. Imanência é o crivo nessa visão, imanência entre problema e solução, invenção e aprendizagem - semelhante à imanência do conceito e seu plano. A defesa é por uma aprendizagem capaz de produzir seus próprios problemas e atualizar sob a forma de conceitos, uma atividade muito próxima do cartógrafo, conforme discutimos no primeiro capítulo. Assim, a aprendizagem em Deleuze é uma experiência caracterizada pela invenção, próprio do fazer filosófico do francês, caracterizada pela criação de conceitos.

Ao concordar com Gallo, Kastrup e Gallina, e diante da hegemonia dos processos recognitivos na escola, da ausência de concepções inventivas de aprendizagem, questionamos qual teoria poderíamos extrair a partir da(s) filosofia(s) da(s) diferença(s) de Deleuze e Guattari que nos ajudassem a enfrentar tais dilemas?

O aprender ocupa, na filosofia de Gilles Deleuze, um lugar de destaque. É um ato de adaptação e de criação, um agenciamento complexo, que concerne às condições de possibilidade do próprio pensamento: formação da Ideia e formulação do problema. O aprender vai além do saber, esposando a vida toda, inteira, em seu curso apaixonado e imprevisível. Schérer (2005) aponta a existência de três balizas para a compreensão de uma teoria do aprender em Deleuze: a fuga de uma concepção de aprendizagem em que as soluções já estão dadas, o direito à invenção problemática 
singular e a fortuidade dos encontros que nos levam ao aprender, varrendo qualquer possibilidade de governo. Mais do que isso, Schérer acredita que Deleuze nos ensinou a remar na contramão da esterilização da criação, a não adentrar correntes doutrinárias da moda, a retirar das sombras potenciais aliados, em busca incessante de novas formulações no pensamento.

Indo no mesmo sentido, Gallo (2017) visualiza a partir das obras "Proust e os signos" e "Diferença e repetição" uma "quase" teoria da aprendizagem deleuziana, um modo de ver a educação que se distancia da filosofia clássica e suas filhas científicas modernas. Nesta combinação, aprender é um encontro com signos, retirando a ênfase na emissão de signos. Ao focalizar os agenciamentos em detrimento de uma ação objetiva, Gallo coloca em jogo a questão do inconsciente - no sentido deleuze-guattariano - no papel da aprendizagem. Tal forma de entender a aprendizagem traz consigo, evidentemente, a imprevisibilidade do processo, a impossibilidade de controle e previsão. Aprender é um processo que somente se entende depois de consumado e, mesmo assim, parcialmente.

Kastrup (1999) persegue a mesma direção por outros rizomas. Para a autora, a história da psicologia demonstra como existe um falso problema da criatividade, pois ela sempre foi entendida como subordinada à inteligência e resolução de problemas. Tais problemas a serem solucionados estão sempre ao serviço dos agenciamentos de poder das máquinas sociais. Assim, dentro da psicologia, a invenção nunca foi de fato um problema. Para superar essa condição, Kastrup utiliza como ponto de partida para sua inferência a discussão foucaultiana sobre a ontologia da verdade. Ao se voltar para o campo da cognição como espaço de representação, as metanarrativas psicológicas modernas formulam a questão pressupondo invariabilidade e exatidão, o que elimina qualquer possibilidade de invenção. "Somente uma mudança na formulação do problema da cognição, o que depende de uma problematização de seus pressupostos filosóficos e epistemológicos, abre a possibilidade para um estudo da invenção" (KASTRUP, 1999, p. 19).

Dentro da bifurcação filosófica da analítica da verdade e a ontologia do presente, a psicologia claramente permaneceu na primeira. A analítica da verdade exclui o tempo como substância do real e é justamente este componente que Kastrup resgata para compor seu pensamento, em aliança com os filósofos Bergson e Deleuze. É preciso enfatizar que aqui invenção não é tratada como criatividade, não é um processo psicológico individual ou possui um sujeito como centro, mas fruto de uma duração temporal que impede distinção entre sujeito e objeto. Kastrup sugere que a psicologia redefina o conceito de cognição colocando foco na invenção e não na recognição, buscando as condições paradoxais de um pensamento que assume formas sempre híbridas, plano de condições de uma cognição ampliada, "que inclua a recognição, mas também a invenção. Condições complexas para uma cognição paradoxal, inventiva e imprevisível" (KASTRUP, 1999, p. 168). Assim, para Kastrup aprender é construir um mundo para si, ao mesmo tempo em que se constrói, em um processo de articulação de multiplicidades que denominou de aprendizagem inventiva.

Ainda que os escritos de Schérer, Gallo, Gallina e Kastrup sejam elucidativos para pensar uma aprendizagem diferencial, acredito que o assunto não apresenta esgotamento. Ao contrário, muito esforço se faz necessário, de modo que me lancei a contribuir de alguma forma.

\section{Esquizoaprender para uma política cognitiva}

A primeira afirmação é da aprendizagem como transformação na subjetividade - é tornarse outros(as). Sendo a subjetividade um processo resultante da dobra do fora no interior, estamos a todo momento sendo subjetivados pelo nosso entorno, pelas possibilidades dos acontecimentos. Chamo de aprender, portanto, a consecução dessa passagem do devir: se entendermos a subjetividade como efeito de um processo que envolve instâncias pré-subjetivas 
e pré-objetivas, o aprender está intensamente conectado com o devir, uma abertura para o tempo: "Aprender é tão-somente o intermediário entre não-saber e saber, a passagem viva de um ao outro" (DELEUZE, 2006, p. 238).

Uma vez que esse movimento é incessantemente atacado por forças que nos encontram, acreditamos em um nomadismo subjetivo subjacente ao processo de aprendizagem, ou mesmo inconfundível. O que essa lógica de processo coloca em xeque é qualquer compreensão de sujeito dado, algo extensamente discutido em todo o nosso trabalho de pesquisa. Vimos também como essa perspectiva é radicalizada em Deleuze, com a perspectiva de um pensamento do fora - algo já presente em Foucault (RIBEIRO, 2011).

Isso não significa que não temos, enquanto indivíduo singular, nenhuma agência sobre a própria produção subjetiva. Dentro de um exercício sempre perigoso de metaforizar, podemos pensar em uma pessoa à deriva nas forças das ondas do mar. O oceano é gigantesco, com ondas em interações complexas e com forças para vários lados, levando nosso náufrago para locais inesperados. Nesse contexto, o nadador não escolheu o ponto de naufrágio, o que tem correlação com nossa história de nascimento; tampouco consegue controlar a massa de água que influencia suas possibilidades, assim como não controlamos as forças que nos acometem pelos encontros, sempre indeterminados, ainda que intuídos. A força que resta ao nadador naufrago é aquela dos seus braços, uma força menor, mas que também compõe no processo de existir.

Em paralelo com a produção subjetiva, não resta ao indivíduo viver como lhe determinam certas forças, mas há possibilidade, ainda que muitas vezes limitada, de agir sobre si. Schérer (2005) acrescenta que, influenciado por Nietzsche, Deleuze apresenta um grande paradoxo: é justamente no exercício de despersonalização que nos aproximamos de falar "em nome próprio" (p. 6), uma intensa abertura às multiplicidades que nos atravessam, uma relação amorosa com os agenciamentos, não submissa.

Compreender melhor as forças que nos atravessam ajudam a intuir a passagem do tempo, uma sensibilidade ao devir que não submete as conexões ao racionalismo neurotizado. A racionalidade, uma intelectualidade aprisionada, é uma inteligência operando "fria" (KASTRUP, 1999). Entendo, então, que aprender por recognição é da ordem da inteligência, enquanto que aprender inventivamente é da ordem da intuição. Acreditamos residir aí a brecha para compreender o processo de aprender inventivamente como uma força de resistência contemporânea, micropolítica cognitiva. No entanto, esse processo, sendo de impossível previsão, mas passível de ser pressentido, demanda esforço para a superação egóica de um eu racionalizado. Não temos controle sobre as forças que irão nos acometer, nos afetar, que produções desejantes serão acopladas, mas há espaço para diferentes modos de ser atravessado.

Como a aprendizagem possui um caráter de desprendimento e transformação de si e as forças que nos acometem são imparáveis, aqui a ênfase está em como o indivíduo vivencia essa experiência - se aflito, apegado a um Eu imaginado e reforçado, ou se desprendido, em fluxo com as forças. São impeditivos da invenção a impossibilidade de autopoiese e obliteração do processo de invenção, processos que acontecem quando o sujeito toma a sua invenção como verdade, um apego ao senso comum da recognição, formando verdadeiros regimes totalitários de subjetividade. Se concordamos que há forças que impedem uma invenção de um si permanente, somente há sedentarismo, portanto, quando se realiza um apego de si, um movimento de retração que se encontra na gênese do sofrimento humano, com efeitos nefastos para a inventividade. O resultado é uma morte que coexiste com a vida, vida sem potência.

De onde vêm tanto os vetores que demandam criação subjetiva, quanto aqueles que encarceram a vontade de potência e performam um apego ao senso comum, senão nos aspectos sociais, culturais, políticos? As máquinas sociais podem, assim, potencializar ou entravar a 
inventividade. A escola, enquanto máquina, age da mesma maneira - lócus que maquina acoplamentos técnicos, sociais e políticos.

Deleuze e Guattari (2011) nos mostram que as subjetividades produzidas no contexto de produção e consumo são fundamentais para a continuidade do socius estatal moderno e independe a posição social ocupada pelos indivíduos. Trabalhadores, consumidores, empresários, chefes, professores, alunos... Todos podem ser subjetivados e se tornar escravos da lógica do capital. Isso explica a defesa que muitos indivíduos subjugados fazem do funcionamento da máquina do capital, pois o capitalismo consegue monetarizar seus limites, reterritorializar fluxos, não permitindo a chegada à esquizofrenia, a ruptura total com os códigos ou territórios. A esquizofrenia é o limite exterior do capitalismo, limite que nunca é atingido. O que é descodificado por um lado, é axiomatizado por outro.

Em tempos de crise econômica, o capitalismo impõe sua demência esquizofrênica acelerando processos de desterritorialização e reterritorialização visando a evitar a sua morte pela baixa tendencial de acúmulo e lucro, o que provoca profundas crises na economia do desejo. Para Guattari e Rolnik (2013), esse processo acelera o descarte de modos de existência, levando-nos a investir em fábricas de subjetividade serializadas, exigindo muita coragem para criar territórios singulares. As redes sociais criadas na era da internet nos dão mostras diárias do sistema. Nesse contexto, subjetividades dissidentes se fazem muito necessárias para a liberação do processo desejante e constituição de territórios singulares. Urge fazer coro aos "inconscientes que protestam" (DELEUZE, 2013, p. 34), privilegiar a produção de linhas de fuga, intensificação de desejo esquizo.

$\mathrm{Na}$ filosofia deleuze guattariana, o desejo faltante é o desejo reacionário, típico das subjetividades capitalistas, desejo preenchido pelos acenos do poder, desejo pelo sucesso, pelo prazer, pela fama, pelo dinheiro, pela vitória, pela competição, pelo individualismo, pela capacidade de oprimir, mandar, determinar, sobrepor. Enquanto máquina aliada ao socius produtivo/consumista, as escolas operam verdadeiras fábricas subjetivas neuróticas, promovendo aprendizagem recognitiva que ignora processos de singularização. Para a produção de outras subjetividades, os autores apontam para a necessidade de uma máquina de guerra que não tenha a guerra por objetivo, mas a luta contra espaços e tempos estriados. A máquina de guerra é o fora do Estado que visa então ocupar e promover espaço e tempo lisos que possibilitem o nomadismo subjetivo, a busca por intensidade que não seja conduzida para fins imersos na lógica produção-consumo que movimenta o ciclo de acúmulo de capital.

Esta luta através da máquina de guerra se dá no nível dos axiomas, no nível da micropolítica, ou uma política menor. As estratégias incluem não permitir que movimentos revolucionários sejam reterritorializados pela máquina estatal, utilizando os axiomas para a produção de novas subjetividades, outros modos de expressão e vida, evitando uma burocratização e acoplamento na máquina capitalística. A busca é pelo que Nietzsche denominou de transvaloração de todos os valores (DELEUZE, 2018).

Como todos são escravos da subjetividade capitalista, o capitalismo é a mais drástica de todas as formações sociais. A luta é, portanto, pela produção de Corpo Sem Órgãos (CsO), pela produção de intensidades, pela composição estética que dista dos fins produção-consumo, uma subjetividade que não deseja o poder, o fascismo, o domínio. A pouca intensidade de vida é facilmente capturada pelos agenciamentos de poder, pois uma vida triste é o primeiro passo para o desejo de dominação. A vida alegre, ativa, que produz inconsciente é, assim, o objetivo da esquizoanálise.

Distante dos movimentos reacionários, podemos entender o desejo esquizo como produtivo, incontrolável, singular, que acontece e escapa das linhas duras das máquinas reguladoras. Sendo esquizo tudo aquilo que escapa, que desvia das normas, nos questionamos se não temos o risco de um mergulho no caos, um olhar para o abismo do qual não há 
possibilidade de reorganização cognitiva, "Será que é possível captar a potência da droga sem se drogar, sem se produzir como um farrapo humano?" (DELEUZE, 2013, p. 35).

Não se trata de defender uma subjetividade caótica. De antemão, afirmamos que não há possibilidade de não se relacionar com o espaço-tempo estriado, mesmo para o nômade, mas a busca é pela subjetividade que não se submete ao Estado (como não há aula sem amarras de poder). O nômade investe sempre que possível no espaço e tempo lisos ao promover uma relação de afetos com os desejos. Logo, máquinas de guerra não reterritorializadas pelo capitalismo continuam a promover então espaços-tempos lisos que permitem potencialização de intensidades que configuram subjetividades nômades, num processo que Guattari e Rolnik (2013, p. 35) denominaram de "processos de singularização da subjetividade".

A mudança social passa, então, pela capacidade de acoplamento com processos de transformação do real. Para combater a escravização desejante imposta pela captura de fluxos do capitalismo, Deleuze e Guattari propõem a esquizoanálise como forma de criação de novas realidades, intensidades, $\mathrm{CsO}$ (conceitos sendo tratados aqui como sinônimos), o que possui um sentido clínico para uma singularidade subjetiva neurótica, uma vez que o neurótico está investido com todas as suas forças no Eu narcísico, mas também há um sentido político afirmativo frente às necessidades do capital. O trabalho da esquizoanálise é, portanto, devolver um sentido afirmativo à própria vida, devolver ao desejo o que foi capturado pela máquina capitalística.

Esquizoanálise, portanto, é uma teoria/prática que propõe novas possibilidades de análise e experimentação do sujeito e do seu campo social. Dentro da Psicologia, sugere uma nova clínica, a clínica das diferenças e do devir (tornar-se). Sob essa perspectiva, o sujeito vai além de seu diagnóstico e de seu teatro edipiano, podendo desconstruir rótulos e definições universais, afirmando-se e intensificando suas capacidades e potências como singularidades. Devemos não confundir o processo de esquizofrenia que é a produção desejante com a condição clínica do esquizofrênico, mesmo que se reconheça a positividade de resistência da loucura, pois é aquele que sofre de não reconhecer a sep aração entre sujeito e objeto, justamente uma das críticas apresentadas acima.

$\mathrm{O}$ esquizo é aquele que se desterritorializa e ao territorializar se faz no processo de reterritorialização, num movimento incessante, nômade, mais capitalista que o capital. A esquizofrenia é o limite absoluto, o fim intensivo do capital. Retomando a aprendizagem com conceito de desejo esquizo, acreditamos que há uma relação estreita, afinal são as potências dos encontros, os acoplamentos maquínicos que levam à zonas de intensidades singulares, em confluência com a produção para si do CsO; Aprender, nesse sentido, é, também, descodificar, produzir linhas de fuga, esquizofrenizar - aprender-esquizo ou esquizoaprender.

Logo, aprender está diretamente ligado à possibilidade de ser afetado, uma vez que não há problematização ou criação em cima daquilo que não nos intensifica. É desta forma que aprender se relaciona ao $\mathrm{CsO}$, precisamente quando há uma recusa em ser um organismo subjugado pelo socius, quando insurge-se a falar por si. Sendo o corpo organizado pelo Estado profundamente delimitado em suas possibilidades, seus atos tornam-se previsíveis e rapidamente é capturado pelo modo capitalista de ser e existir. Contudo, o CsO não comporta fechamentos, quer ser rachadura - corpo fendido (MOSSI, 2015), inventar e ter direito aos próprios problemas. Assim, aprender é, também, inventar um CsO para si.

Se entendermos a invenção de si e do mundo (KASTRUP, 1999) como movimentos de problematizações, de pensar o impensado, cabe pensar o processo a partir de processos desejantes que se contrapõem a ordem dominante Esquizoaprender é um ato político, uma política cognitiva (KASTRUP; TEDESCO; PASSOS, 2015), uma maneira de enfrentar a homogeneização estética das semióticas capitalistas. Nesse sentido, aprender de forma esquizo é uma esquizopolítica (CARVALHO, 2019). 


\section{Por uma política cognitiva}

Defendemos, então, uma cognição ampliada, distante dessa visão limitante e inseparável tanto dos devires que cavam rachaduras nos esquemas recognitivos, quanto do coletivo, em que seu poder inventivo se amplifica. Assim, o aprendizado empreende um movimento rizomático. A cada ampliação rizomática, não se descobre uma verdade, mas atualiza-se uma virtualidade. Em termos práticos, significa que não existem conhecimentos fundamentais no ensino, não há base alguma, mas conexões absolutamente descentradas - o que desfere um golpe mortal em termos muito caros na filosofia da educação, termos como estágios, fases etc.

A aprendizagem não busca o antecipável e acaba por encontrar o imprevisto. Logo, como afirmado muitas vezes por outros argumentos, a aprendizagem é um processo do qual não temos controle. Se o viver é autopoiético, a cognição deve ser dita invenção, cujos dois resultados, cujos dois inventos, igualmente imprevisíveis, são a estrutura da cognição e o mundo conhecido. Conceber a aprendizagem como processo diferencial demanda superação do projeto moderno de purificação das formas, que impede a compreensão do hibridismo entre indivíduo e sociedade, aprendizagem em redes múltiplas potencializada pelas novas técnicas.

Esquizoaprender é, em sentido primordial, invenção de problemas, cognição em devir. Mas a abertura ao devir não diz tudo sobre a invenção, pois necessita ainda da produção. Produção de si indissociável de uma produção de mundo, formas ad hoc, agenciadas coletivamente e maquinicamente pelo desejo. Isso somente acontece na prática com a matéria, na enação, pois o processo de aprendizagem acarreta invenção de problemas.

\section{Referências}

CARVALHO, A. F. É possível outros pontos de subjetivação em um mundo insano? microteses de esquizoanálise para nós na educação. In: CORRÊA, M.; CABALLERO, A.; VERDÚ, M. (Org.). Do caos ao cais e vice-versa: intersecções entre ciência, filosofia e arte. Campinas: Gráfica FE, 2019. p. 12-34.

DELEUZE, G. Diferença e repetição. 2. ed. Rio de Janeiro: Graal, 2006.

DELEUZE, G. Foucault. São Paulo: Brasiliense, 2013.

DELEUZE, G. Nietzsche e a filosofia. São Paulo: N-1 edições, 2018.

DELEUZE, G.; GUATTARI, F. O anti-Édipo. 2. ed. São Paulo: Editora 34, 2011.

GALLINA, S. F. S. Invenção e aprendizagem em Gilles Deleuze. 2008. Tese (Doutorado em Educação) - Faculdade de Educação da Unicamp, Campinas, 2008.

GALLO, S. D. O. Deleuze e a educação. Belo Horizonte: Autêntica, 2013.

GALlo, S. D. O. O aprender em múltiplas dimensões. Revista do Programa de PósGraduação em educação Matemática da Universidade Federal de Mato Grosso Do Sul (UFMS), v. 10, n. 22, p. 103-114, 2017 [Seção Temática].

GUATTARI, F.; ROLNIK, S. Micropolítica: cartografias do desejo. 12. ed. Petrópolis: Vozes, 2013. 
KASTRUP, V. A invenção de si e do mundo: uma introdução do tempo e do coletivo no estudo da cognição. Campinas: Papirus, 1999.

KASTRUP, V.; TEDESCO, S.; PASSOS, E. Políticas da cognição. Porto Alegre: Sulina, 2015.

MOSSI, C. P. Teoria em ato: o que pode e o que aprender um corpo? Educação e Pesquisa, São Paulo, v. 41, n. especial, p. 1541-1552, dez. 2015.

RIBEIRO, C. R. "Pensamento do fora", conhecimento e pensamento em educação: conversações com Michel Foucault. Educação e Pesquisa, São Paulo, v. 37, n. 3, p. 613-628, set./nov. 2011.

SCHÉRER, R. Aprender com Deleuze. Educação e Sociedade, Campinas, v. 26, n. 93, p. 1183 1194, set./dez., 2005. 